\title{
Irrigation Scheduling Using Remote Sensing Data Assimilation Approach
}

\author{
Baburao Kamble ${ }^{1}$, Ayse Irmak ${ }^{1}$, Kenneth Hubbard ${ }^{1}$, Prasanna Gowda ${ }^{2}$ \\ ${ }^{1}$ University of Nebraska-Lincoln, Lincoln, USA \\ ${ }^{2}$ USDA-ARS, Bushland, USA \\ Email: bkamble3@unl.edu
}

Received February 28, 2013; revised March 28, 2013; accepted April 28, 2013

Copyright (C) 2013 Baburao Kamble et al. This is an open access article distributed under the Creative Commons Attribution License, which permits unrestricted use, distribution, and reproduction in any medium, provided the original work is properly cited.

\begin{abstract}
Remote sensing and crop growth models have enhanced our ability to understand soil water balance in irrigated agriculture. However, limited efforts have been made to adopt data assimilation methodologies in these linked models that use stochastic parameter estimation with genetic algorithm (GA) to improve irrigation scheduling. In this study, an innovative irrigation scheduling technique, based on soil moisture and crop water productivity, was evaluated with data from Sirsa Irrigation Circle of Haryana State, India. This was done by integrating SEBAL (Surface Energy Balance Algorithm for Land)-based evapotranspiration (ET) rates with the SWAP (Soil-Water-Atmosphere-Plant), a processbased crop growth model, using a GA. Remotely sensed ET and ground measurements from an experiment field were combined to estimate SWAP model parameters such as sowing and harvesting dates, irrigation scheduling, and groundwater levels to estimate soil moisture. Modeling results showed that estimated sowing, harvesting, and irrigation application dates were within \pm 10 days of observations and produced good estimates of ET and soil moisture fluxes. The SWAP-GA model driven by the remotely sensed ET moderately improved surface soil moisture estimates suggesting that it has the potential to serve as an operational tool for irrigation scheduling purposes.
\end{abstract}

Keywords: Artificial Neural Network; Genetic Algorithms; SEBAL; Remote Sensing; Groundwater; Crop Growth Modeling

\section{Introduction}

Water scarcity is causing more pressure on utilization of fresh water resources in irrigated agriculture [1]. Therefore, a paradigm shift is necessary from a supply driven into a more demand driven water management. It is recognized that appropriate irrigation scheduling should lead to improvements in water management performance, especially at a farm level [2]. Evapotranspiration (ET) is one of the components of water use efficiency and resulting crop productivity. Periodic information of ET based on remote sensing would be very useful to reduce uncertainty in the crop model parameters and subsequent accurate estimation of the water balance. Several algorithms have been developed to utilize remote sensing data for quantifying ET [3-9]. Researchers have also reviewed different ET algorithms [10] and used remotely sensed data in conjunction with crop or hydrological models via data assimilation for improving soil moisture estimation [11-14]. Researchers also used the Ensemble Kalman Filter (EnKF) with daily microwave observa- tions over an eight-day period, as well as through a cropping season for estimating soil moisture fluxes [11]. Studies were showed the concept of optimal downscaling for a case where soil moisture estimates were required at scales smaller than that of the microwave observations [14]. An extensive review was conducted on soil water simulation model that uses remotely sensed data to predict moisture in soil profiles [12,15-17]. Ines and Honda developed an assimilation methodology [12] for the Soil, Water, Atmosphere, and Plant (SWAP) simulation model [18] with remote sensing data using Genetic Algorithm (GA) [19]. Similar work was done at spatial scale [20] with an objective to fuse remote sensing data.

Given the above background, the emphasis of this study was to develop a comprehensive data assimilation approach for scheduling on-demand irrigation using SWAP model predictions and SEBAL (Surface Energy Balance Algorithm for Land) based ET [5]. This methodology was implemented using a GA to estimate values for SWAP's sensitive input parameters and by updating 
SWAP-ET predictions with SEBAL-ET. This was achieved by (a) estimating ET from MODIS (Moderate Resolution Imaging Spectroradiometer) data using SEBAL, (b) developing an ET data assimilation scheme with a GA to optimize SWAP input parameters for scheduling irrigation, (c) validating optimized parameters with the observations made at the experimental site, (d) evaluating the potential use of optimized parameters for irrigation scheduling with two separate runs of SWAP model with and without optimizer, and (e) simulating and comparing yield and water use efficiency under different irrigation scenarios for an irrigated cotton field in the Sirsa Irrigation Circle (SIC) located in Haryana, India (Figure 1). The irrigation circle is an administrative irrigation unit managed by the Haryana Irrigation Department $[21,22]$.

\section{Materials and Methods}

\subsection{Study Area}

The proposed approach was tested using a dataset on irrigated cotton field in the SIC (Figure 1). Data used in this study was collected as part of another study conducted by the Wageningen Agricultural University, The Netherlands during 2002 for calibrating the SWAP model. The hourly meteorological measurements (Fig-

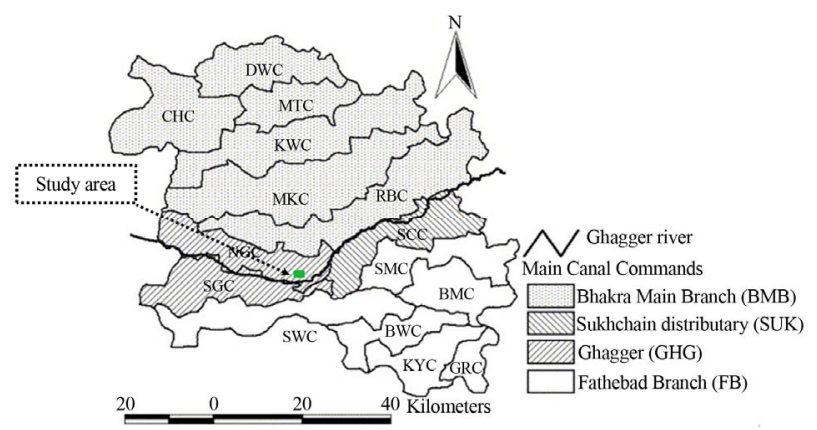

Figure 1. The location of the study area (green rectangle) within Sirsa Irrigation Circle (CIS), Haryana, India. ure 2) included air temperature, wind speed, solar radiation, and precipitation from a weather station installed at the Indian Council of Agricultural Research-Cotton Research Institute (ICAR-CRS) (latitude 29 35' North; longitude $75^{\circ} 08^{\prime}$ East) located within the SIC (Figure 1). The SIC is located in the extreme western part of Haryana between latitudes $29.1^{\circ}$ and $30.0^{\circ}$ North and longitudes $74.2^{\circ}$ and $75.3^{\circ}$ East. The climate of the SIC area is characterized by semi-arid and short, mild, variably wet monsoons. The climate of this SIC is characterized by its dryness and extremes temperatures and scanty rainfall. Based on long-term records, January is coldest month with daily minimum temperature $5^{\circ} \mathrm{C}$ and May/June is hottest month with temperature rises up-to $45^{\circ} \mathrm{C}$. The average annual precipitation in Sirsa Irrigation Circle varies from 100 to $400 \mathrm{~mm}$, which is only $10 \%-25 \%$ of the potential evapotranspiration of common crop rotations. The precipitation mainly occurs during monsoon months of July to September [21]. Ground surface elevations vary from 192 to $207 \mathrm{~m}$ above mean sea level. Rice-wheat cropping system is the major cropping system in the SIC. Use of comparative short-duration (100 120 days after transplanting) of rice and wheat (135 to 150 days) wheat varieties has offered a unique opportunity for extension of area under a two -crops-a-year. [17, 21-23].

The total area of the SIC is $44,200 \mathrm{~km}^{2}$ with about $82 \%$ of the area under cultivation. At present, only $40 \%$ of the total cultivated area is under surface (canal) water irrigation. Water management in the SIC, like any other arid or semi-arid regions in the developing world, is very complex in nature. Key characteristics of the SIC are: a) scarce and erratic precipitation with no perennial rivers in and around the area, b) high evaporative demand, c) marginal to poor quality groundwater in most parts, d) rising groundwater levels with occasional flooding, and e) low water-holding capacity of soils.

Other factors affecting water use efficiency and crop production include fluctuations in canal water supply,

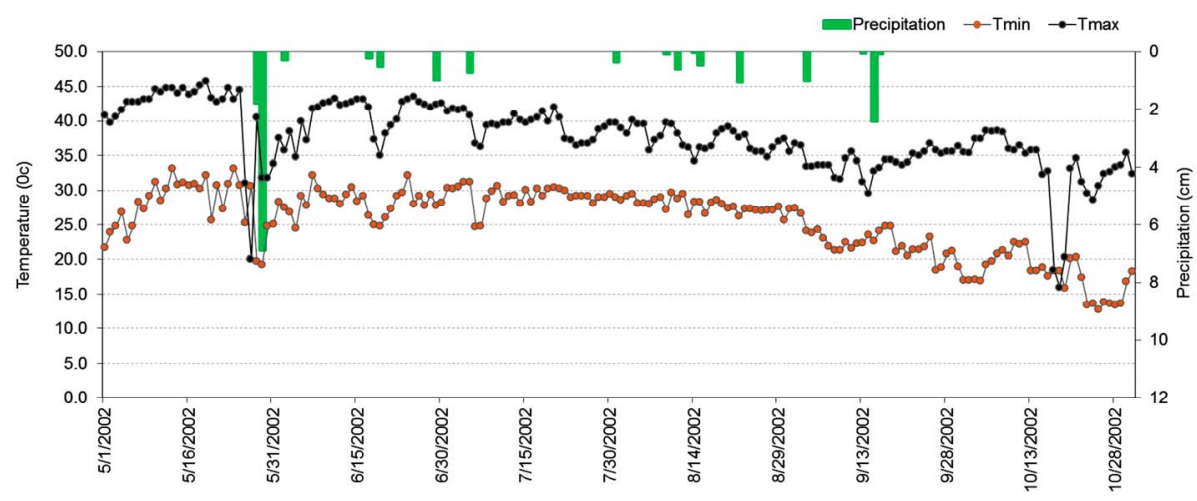

Figure 2. Measured daily values of minimum and maximum temperature, humidity and precipitation, in Sirsa district during the agricultural year 2002 . 
low irrigation application efficiency due to light textured soils, and conveyance losses from the irrigation system $[21,23]$. A summary of the physical properties of soil at the time of sowing of cotton is presented in the Table $\mathbf{1}$. The soil at the experimental site was a typical sandy loam with $8 \%-17 \%$ clay, $10 \%-16 \%$ silt and $60 \%$ $80 \%$ sand with $0.5 \%$ organic matter, electrical conductivity rate of $0.15 \mathrm{dS} / \mathrm{m}$, and $\mathrm{pH}$ of 8.5 with bulk density $1.65 \mathrm{gm} / \mathrm{cc}$ with low water-holding characteristics. Table 1 shows soil physical properties measured in the experimental field. Soil water content measurements were

Table 1. Physical properties of soil of field at the time of sowing of cotton.

\begin{tabular}{|c|c|c|c|c|c|}
\hline \multirow{2}{*}{ Parameter } & \multirow{2}{*}{ Unit } & \multicolumn{4}{|c|}{ Depth (cm) } \\
\hline & & $0-15$ & $15-30$ & $30-60$ & $60-90$ \\
\hline Textural class & Name & $\begin{array}{l}\text { Sandy } \\
\text { loam }\end{array}$ & $\begin{array}{l}\text { Loamy } \\
\text { sand }\end{array}$ & $\begin{array}{l}\text { Loamy } \\
\text { sand }\end{array}$ & $\begin{array}{l}\text { Sandy } \\
\text { loam }\end{array}$ \\
\hline Clay & $(\%)$ & 11.15 & 9.82 & 8.94 & 10.31 \\
\hline Silt & $(\%)$ & 11.77 & 10.74 & 10.07 & 13.04 \\
\hline Sand & $(\%)$ & 77.08 & 79.44 & 80.99 & 76.29 \\
\hline $\begin{array}{l}\text { Soil moisture at } \\
\text { saturation }\end{array}$ & $(\%)$ & 31.3 & 31.2 & 31.5 & 35.7 \\
\hline $\begin{array}{l}\text { Saturated hydraulic } \\
\text { conductivity }\end{array}$ & $\mathrm{cm} / \mathrm{hr}$ & 4.932 & 4.012 & 5.037 & 5.011 \\
\hline Bulk density & $\mathrm{g} / \mathrm{cc}$ & 1.65 & 1.69 & 1.65 & 1.63 \\
\hline
\end{tabular}

made in the top two soil layers $(0-15 \mathrm{~cm}$ and $15-30 \mathrm{~cm})$ using a gravimetric sampling method for seven times during 2002.

There were about 15 - 20 soil samples takenfor gravimetric analysis on each measurement day and soil moisture was estimated based on volumetric basis (\% moisture on dry weight basis $\times$ bulk density). The study field was irrigated from a tube-well with a discharge of 64.76 $\mathrm{m}^{3} / \mathrm{hr}$.

\subsection{Satellite Data Processing}

The MODIS Level 1B (L1B) images (radiometrically corrected) of the Indo-gangatic area covering the SIC were downloaded from the Earth Observing System Data Gateway of NASA (National Aeronautics and Space Administration). Although MODIS images were available for every $1-2$ days, there were only 13 cloud-free MODIS images from eight day composites available to estimate seasonal ET for the Kharif (summer) growing season (5/2002-10/2002). Table 2 shows the details of MODIS products used in the study. A subset image for the study area was extracted for better visualization and computationally efficient analysis of satellite data. The MOD11 L2 data comprised of two thermal bands with a $1 \mathrm{~km}$ resolution and was used to estimate surface temperature and emissivity. Extraction of the binary files was performed for two visible (bands 1 and 2), five short-wave infrared (bands 3-7) and two thermal (31 and

Table 2. MODIS data products used in the analysis.

\begin{tabular}{|c|c|c|c|c|}
\hline Data set & Data Type & Fill Value & Valid range & Scale Factor \\
\hline \multicolumn{5}{|c|}{ MOD09: MODIS Terra Surface Reflectance (500 m) } \\
\hline Surface Reflectance Band 1 (620 - 670 nm) & 16-bit signed integer & -28672 & $-100-18,000$ & 0.0001 \\
\hline Surface Reflectance Band 2 (841 - 876 nm) & 16-bit signed integer & -28672 & $-100-18,000$ & 0.0001 \\
\hline Surface Reflectance Band 3 (459 - 479 nm) & 16-bit signed integer & -28672 & $-100-18,000$ & 0.0001 \\
\hline Surface Reflectance Band 4 (545 - 565 nm) & 16-bit signed integer & -28672 & $-100-18,000$ & 0.0001 \\
\hline Surface Reflectance Band 5 (1230 - 1250 nm) & 16-bit signed integer & -28672 & $-100-18,000$ & 0.0001 \\
\hline Surface Reflectance Band 6 (1628 - 1652 nm) & 16-bit signed integer & -28672 & $-100-18,000$ & 0.0001 \\
\hline Surface Reflectance Band 7 (2105 - 2155 nm) & 16-bit signed integer & -28672 & $-100-18,000$ & 0.0001 \\
\hline Granule Time & 16-bit signed integer & 0 & $0-2355$ & 1 \\
\hline \multicolumn{5}{|c|}{ MOD11: MODIS Land Surface Temperature and Emissivity (1000 m) } \\
\hline Land Surface Temperature & 16-bit signed integer & 0 & $7500-65,535$ & 0.02 \\
\hline Band 31 emissivity & 8-bit unsigned integer & 0 & $1-255$ & 0.002 \\
\hline Band 32 emissivity & 8-bit unsigned integer & 0 & $1-255$ & 0.002 \\
\hline Local solar time of Land-surface Temperature observation & 8-bit unsigned integer & 0 & $0-240$ & 0.1 \\
\hline
\end{tabular}


32) bands. The original MODIS data was provided in HDF (Hierarchical Data Format). A HEG conversion tool (http://gcmd.nasa.gov/ records/HEG.html) was used to convert the HDF files into Geo TIFF images. Individual images of each band were created for each day by converting their corresponding HDF files. Our experiment field size was about $4386 \mathrm{~m}^{2}$, which was less than one pixel $(1 \times 1 \mathrm{~km})$ in MODIS thermal image. MODIS LST (Land Surface Temperature) product was downscaled to $250 \mathrm{~m}$ using a cubic convolution technique to be consistent with the spatial resolution of MODIS visible and near infrared (MOD09) data. For geo-rectification, we have changed the projection from sinusoidal to UTM with a WGS84 datum. This ended up with gridded data for which both the geographic coordinate system and the projected coordinate system are defined in terms of the WGS84 ellipsoid.

\subsection{Evapotranspiration Mapping with SEBAL}

SEBAL is a remote sensing based algorithm that computes a complete surface energy balance along with resistances for momentum, heat and water vapor transport for each pixel [5]. Land surface parameters such as surface albedo, vegetation index, emissivity, and surface temperature were derived from MODIS data using the SEBAL. The key input data for SEBAL consists of spectral radiance in the visible, near-infrared and thermal infrared part of the electromagnetic spectrum. In addition to MODIS data, the SEBAL requires routine weather data parameters (wind speed, humidity, solar radiation and air temperature). Under the absence of advection, the energy balance in SEBAL is calculated at an instant time $\mathrm{t}$ for each satellite overpass by the following equation:

$$
R_{n}=\lambda E+H+G
$$

where $R_{n}$ is the net radiation $\left(\mathrm{W} / \mathrm{m}^{2}\right), \mathrm{G}$ is the soil heat flux $\left(\mathrm{W} / \mathrm{m}^{2}\right), \mathrm{H}$ is the sensible heat flux $\left(\mathrm{W} / \mathrm{m}^{2}\right)$, and $\lambda \mathrm{E}$ is the latent heat flux which is the energy necessary to vaporize water $\left(\mathrm{W} / \mathrm{m}^{2}\right)$. The $\lambda E$ under given atmospheric conditions can be calculated as a residual of the energy balance components in Equation (1). The instantaneous evaporative fraction $(\Lambda$, dimensionless) is an expression to obtain the actual ET when the atmospheric moisture conditions are in equilibrium with the soil moisture conditions. The $\Lambda$ is used to calculate the daily value based on the assumption that the evaporative fraction is constant during daytime hours under non-advective conditions [5]:

$$
\Lambda=\frac{\lambda E}{\lambda E+H}=\frac{\lambda E}{R_{n}-G}
$$

where daily actual evapotranspiration $\left(\mathrm{ET}_{24}\right)$ is calculated from the $\Lambda$, and the $R_{n}$ integrated over the 24-h period $\left(R_{n 24}\right)$. According to assumptions made in the SEBAL model, net available energy $\left(R_{n}-G\right)$ reduces to $R_{n}$ at daily timescales. $E T_{24}$ is computed as:

$$
E T_{24}=\frac{86400 X 10^{3}}{\lambda \rho_{w}} R_{n 24}
$$

where $R_{n 24}$ is the $24-\mathrm{h}$ averaged net radiation $\left(\mathrm{W} / \mathrm{m}^{2}\right), \lambda$ is the latent heat of vaporization $(\mathrm{J} / \mathrm{kg}), \rho_{\mathrm{w}}$ is the density of water $\left(\mathrm{kg} / \mathrm{m}^{3}\right)$ and $E T_{24}$ is daily actual ET (mm/day).

\subsection{Soil-Water-Atmosphere-Plant (SWAP) Model}

An intermediate version of the SWAP model (SWAPGA) [12] was used in this study. The SWAP is a physiccally based one-dimensional model that simulates vertical transport of water flow, solute transport, heat flow and crop growth at the field scale level [16]. It requires inputs including management practices and environmental conditions to compute a daily soil water balance and crop growth. The major processes taken into account are phenological development, assimilation, respiration and ET. The SWAP model uses Richard's equation [24] to simulate vertical soil water movement in variably saturated soils as follows:

$$
\frac{\delta \theta}{\delta t}=\frac{\partial}{\partial z}\left[K(\psi)\left(\frac{\partial \psi}{\partial z}+1\right)\right]
$$

where $K$ is the hydraulic conductivity $\left(\mathrm{cm} \cdot \mathrm{d}^{-1}\right), \psi$ is the pressure head $(\mathrm{cm}), z$ is the elevation above a vertical datum $(\mathrm{cm}), \theta$ is the water content $\left(\mathrm{cm}^{3} \cdot \mathrm{cm}^{-3}\right)$, and $t$ is time (d). The soil hydraulic functions in the model are defined by the Mualem-Van Genuchten (MVG) equations [25] which describe the capacity of the soil to store, release and transmit water under different environmental and boundary conditions. Darcy's law is used to determine potential soil evaporation in wet soil conditions. Root water extraction at various depths in the root zone is calculated from potential transpiration, root length density and possible reductions due to wet, dry, or saline conditions. The SWAP also integrates the basic WO FOST (World Foods Tudies) crop growth model and was frequently used to study the effect of the climate change on crop production [12,17,20-22]. Water requirements of a crop depend mainly on crop growth stage and environmental conditions. Root water uptake estimated by model does not depend on the rooting density but only on the actual rooting depth and available soil water. Different crops have different water-use requirements under the same weather conditions. SWAP model simulation gives the balance of water inputs from precipitation and from addition of water to root zone by root growth and water losses computed by crop transpiration, soil evaporation, and percolation to deep soil layers, which gives a complete picture of the water availability and water con- 
sumption in particular cropping system [18].

\subsection{Optimization Scheme}

The SWAP-GA model relies heavily on assimilation of land surface data, which has shown significant potential to improve the realistic representation of the land surface condition. The objective of data assimilation is to obtain the best estimate of the state of the system by combining observations with the forecast model's first guess. Genetic algorithms (GA) technique is a function of optimization derived from the principles of evolutionary theory. It is designed to search, discover, and emphasize optimum solutions by applying selection and crossover techniques, inspired by nature, to supply solutions $[19,26]$. GA operates on pieces of information as nature does on genes in the course of evolution. It has good global search characteristics. Three operators are designed to modify individuals: selection, mutation and crossover [27]. The evolution usually starts from a population of randomly generated individuals and happens in generations. In each generation, the fitness of every individual in the population is evaluated; multiple individuals are stochastically selected from the current population based on their fitness, and recombined and possibly randomly mutated to form a new population. The new population is then used in the next iteration of the algorithm. The strength of GA with respect to other local search algorithms (lookup table method, ant colony etc,) is to derive more strategies which can be adopted together to find individuals to add to the mating pool, both in the initial population phase and in the dynamic generation phase. Thus, a more variable search space can be explored at each step. Based on the above biological evolution idea, a so-called "SWAP-GA" has been developed by researchers [12] to estimate input parameters of SWAP from remote sensing data.

Based on the above biological evolution idea, a socalled "SWAP-GA" [12] to estimate input parameters of SWAP from remote-sensing data. The model was adopted and recoded according to the objectives of this research. Cotton is grown in Kharif (April-October) season in the Haryana State of India. Time of sowing spread over a period of April to first fortnight of June. The op- timized parameters were planting date, crop growth period, starting date of irrigation scheduling, and the groundwater depth at the start and end of the simulation (Table 3). The proposed parameters were fed to SWAP by GA according to the objective function. The GA searches for an optimum crop parameter set, while SWAP tests the proposed parameters simultaneously by using them in forward simulations. We compared the results from GA for different populations and different generations. Best results were obtained by applying the algorithm that was configured for 100 populations and 100 generations with up to five optimized crop growth parameters (emergence day, time extent of crop, start of irrigation scheduling, groundwater at start of season, groundwater at end of season). We also optimized two parameters that represent depths to ground water at start of season, groundwater at end of season. There was no reliable field information available to check the validity of these parameters.

Optimizing groundwater at start of season allowed us to initialize water table at the beginning of the simulation. In general, the introduction of a priori information improves the convergence and accuracy of the derived parameters, even in cases where the a priori information is slightly erroneous.

Consider $C$ as the cost function having $(x, y, d)$ parameters. The $x$ and $y$ define coordinates of a pixel location, with $x$ being the longitude [0-180/E-W], $y$ being the latitude $[0-90 / \mathrm{N}-\mathrm{S}]$ and $d$ is the satellite overpass date $[i, \ldots, j]$.

$$
C_{x y d}=\sqrt{\frac{\left(E T_{\mathrm{SEBAL}}-E T_{\mathrm{SWAP}}{ }^{2}\right)}{n}}
$$

where $E T_{\text {SEBAL }}$ is estimated $E T$ via the SEBAL model using remotely sensed data $(\mathrm{cm})$, as the "observed" data for the experimental field in the SIC. $E T_{\mathrm{SWAP}}$ is estimated actual ET from SWAP-GA and based on optimized model parameters, $n$ is the time domain as number of satellite images (sum of $i$ to $j=13$ ) and $C_{x y d}$ is the objecttive function (root mean square error: RMSE) for the pixel at $x, y$ location $(\mathrm{cm})$ and $i-j$ are satellite image dates. When a minimum-difference defined threshold was reached, SWAP parameters were stored for reconstruct-

Table 3. Definition, unit, minimum, and maximum values of optimized parameters in SWAP-GA.

\begin{tabular}{ccccc}
\hline Optimized parameters & Definition & Unit & Minimum value & Maximum value \\
\hline DEC & Emergence day & Ordinal day & 140 & 160 \\
TC & Time extent of crop & Ordinal day & 100 & 200 \\
STS & Start of irrigation scheduling & Ordinal day & 140 & 160 \\
GW $_{\text {jan }}$ & Groundwater at start of season & $\mathrm{cm}$ & 140 & 160 \\
$\mathrm{GW}_{\text {dec }}$ & Groundwater at end of season & $\mathrm{cm}$ & 140 & 160 \\
\hline
\end{tabular}


tion of ET for any required day in the cropping season. We tested the procedure assuming that some degree of error in remote sensing observations $\left(E T_{\text {SEBAL }}\right)$. The fitness of an individual having $x, y$ pixel location characteristics is the inverse of the cost function times the constraints aimed at minimizing the RMSE between SWAP ET and target SEBAL ET. Each water balance parameter after optimization is estimated for kharif growing period to calculate water use efficiency based on Yield/Transpiration, Yield/Evapotranspiration, and Yield/Irrigation. This will evaluate the phenomena with respect to the yield of new irrigation scheme.

We used regression analysis, and root mean square error to evaluate the simulation results. Regression analysis gives information on the relationship between the observed ET variable and the predicted ET variable to the extent that information is contained in the data. To evaluate the performance of the soil moisture simulation, coefficient of determination was used as a relative index of model performance, and root mean square error (RMSE) was used to compare the observed soil moisture and predicted soil moisture. This gave an indication of both bias and variance from the 1:1 line. The RMSE provides a good measure of how closely two independent data sets match.

\section{Results and Discussion}

\subsection{Estimation of Evapotranspiration with SEBAL Model}

During 2002 Kharif season, the actual ET via SEBAL model has been quantified for a cotton field in the SIC. The selection of study area is from homogenous cropping practice region which is suitable for applying low spatial resolution remote sensing $[16,17,20]$. Therefore, the signal in the specific pixel of study area represents the actual electromagnetic characteristics of the cotton. Figure 3 shows the temporal distribution of normalized differ- ence vegetation index (NDVI) and remote sensing estimated ET over the experimental field for Kharif 2002 growing season. Multidate satellite data provide the information of the different stages of the crop. Figure 3 shows the NDVI varied from 0.1 around 1 May to 0.3 at flowering stage (early June) where photosynthetic capacity of a cotton leaf depends on its age. Leaf area index (LAI) and NDVI curves demonstrated gradual increase or decrease in their values with changes in precipitation in early and mid-season. The irrigation demand of cotton increases with increase in NDVI or with increasing photosynthetic rate and vice-versa. NDVI gives important information on the amount of area exposed to the atmosphere for photosynthesis. Soil water availability has direct relation with stomatal behavior and is ultimately related to the photosynthetic process of that crop [14]. Changing progression of ET over cotton crop followed the trend in NDVI during the growing season except for satellite overpasses in mid-September, 2002 (Figure 3) which shows the low NDVI and high ET values. This might be because of occurrence of precipitation, climatological conditions or changes in land use within the MODIS pixel covering the study field. The ET for the study field was low early in the season and varied from 0.01 to $0.2 \mathrm{~cm} /$ day for months when the soil was bare and open. During crop development and mid-season stages, ET varied from $0.3 \mathrm{~cm} /$ day to $0.46 \mathrm{~cm} /$ day. This is due to available soil water via irrigation and precipitation events occurred during that period. After mid-season, ET varied between $0.2 \mathrm{~mm} /$ day and $0.4 \mathrm{~mm} /$ day, ET declined to $0.3 \mathrm{~mm} /$ day at the time of harvesting. However, ET continued to increase in the experimental field even after the NDVI reached its maxima. This may be due to the saturation of NDVI after reaching a certain leaf area index (LAI). Figure 3 shows NDVI is declining from 0.5 in mid-September to 0.1 in mid-October and during this period, LAI increased from about 4 to 6 . The differences in NDVI may partly be due to change in landuse or dif-

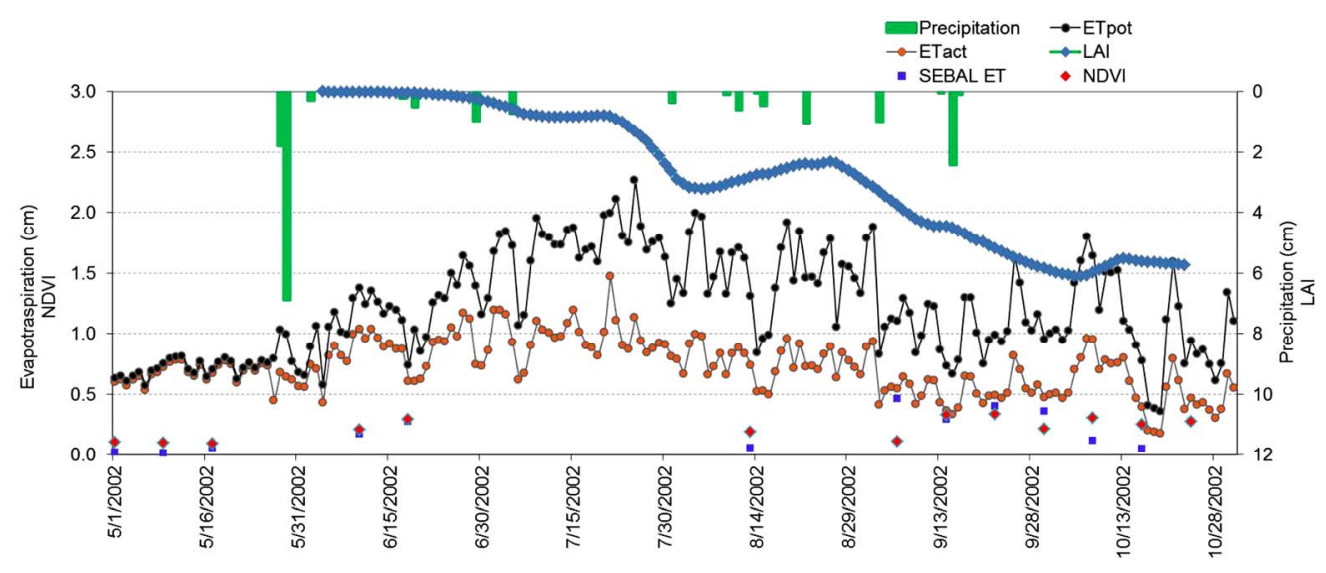

Figure 3. Temporal distribution of LAI, NDVI and evapotranspiration (ET) during the Cotton growing season in the study area. 
ferences in timing and amount of irrigation in the surrounding fields that fall within the study pixel.

\subsection{Remotely Sensed Evapotranspiration Data Assimilation in Hydrological Model}

Figure 4 compares temporal distribution of SEBAL based ET and SWAP-GA based ET, two curves shows similar trends of under and over estimations of actual ET. The SWAP-GA marginally overestimated than the SEBAL based ET in early season when the soil surface was dry and underestimated late in the season when the soil surface was wet and covered by the crop, which influences efficiency of water use, high water productivity and efficient farming activities. The larger ET differences between SWAP-GA and SEBAL were found during May 2002 and June 2002 with a mean absolute difference of $4 \mathrm{~mm} /$ day. However, mean absolute difference was increased to $5 \mathrm{~mm} /$ day when simulations were made without data assimilation. This difference has huge impact on estimating irrigation demand and scheduling. During early in the growing season, the bias far exceeded the actual values. The main reasons for this bias are over estimation of SEBAL-ET and model considers no transpiration till plant emergence.

The SWAP-GA system tries to minimize the difference between SWAP model and SEBAL-ET and the difference between the SWAP-GA and SEBAL ET minimized to $0.25 \mathrm{~mm}$. On August 13, 2002 (Figure 4), the difference between SEBAL-ET and SWAP-GA-ET was about $8 \mathrm{~mm}$ and it was because the SWAP-GA model usually overestimates ET right after irrigation application or a precipitation event (any citation). The data assimilation results in Figure $\mathbf{4}$ are promising but further refinement is necessary to improve the propagation of the correction to the domain outside the assimilation points caused by mixed pixels and to get better bias estimates. The bias due to the comparison of pixel observations with the model needs to be explicitly taken into account to prevent unnecessary forcing of the model towards biased observations. In our case, there is a bias due to the comparison of SEBAL pixel observations with the SWAP-GA model.

\subsection{Optimization of Crop Growth Parameter Using SWAP-GA Model}

SWAT-GA model parameters were optimized by minimizing the RMSE between SWAP-GA-ET and the target SEBAL-ET values and resulting parameter values were used as input for simulating irrigation scheduling. Generally, remote sensing based ET values contains errors due to errors associated atmospheric correction of the reflectance data and due to errors associated with ET algorithms.

Furthermore, coarser resolution, multispectral images such as MODIS have mixed pixel problems which makes it more complicated if the selected pixel exhibits some heterogeneity on the high spatial resolution satellite image. Table 4 shows the values of optimized parameters as well as data from the experimental field. Optimized parameter values with SWAP-GA were closely matched with field measurements. The simulated cropping period from planting to harvest was 169 days against the actual period of 179 days. The depth of groundwater (water table) about $-141 \mathrm{~cm}$ to $-151 \mathrm{~cm}$ is not uncommon in irrigated cotton cropping areas in the SIC [21,22], espescially considering an inundated condition at the start of the period of study.

\subsection{Soil Moisture Based Irrigation Scheduling Scheme}

Figure 5 shows time series observed and simulated soil water contents $\left(\mathrm{cm}^{3} / \mathrm{cm}^{3}\right)$ at $0-15 \mathrm{~cm}$ and $15-30 \mathrm{~cm}$ soil depths and at $30-60 \mathrm{~cm}$ and $60-90 \mathrm{~cm}$ soil depths in Figure 6. About 50 - 60 percent of the total water uptake

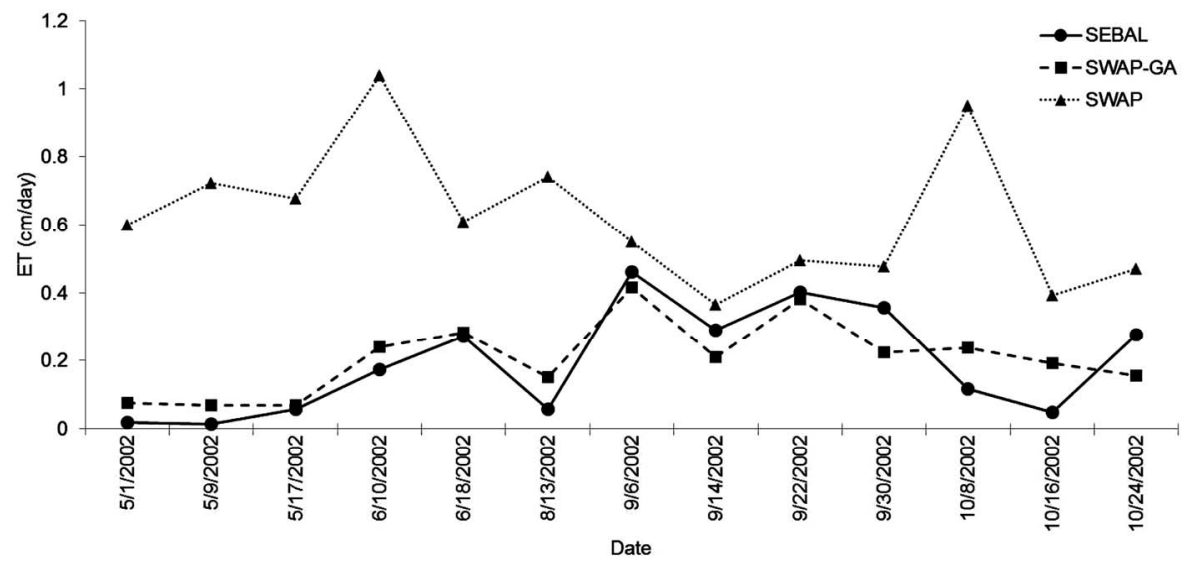

Figure 4. Actual evapotranspiration (cm/day) for the 2002 cotton growing seasons. Observed ET is based on SEBAL algorithms (SEBAL ET) on satellite overpass dates. ET predictions are with original SWAP and SWAP-GA models. 


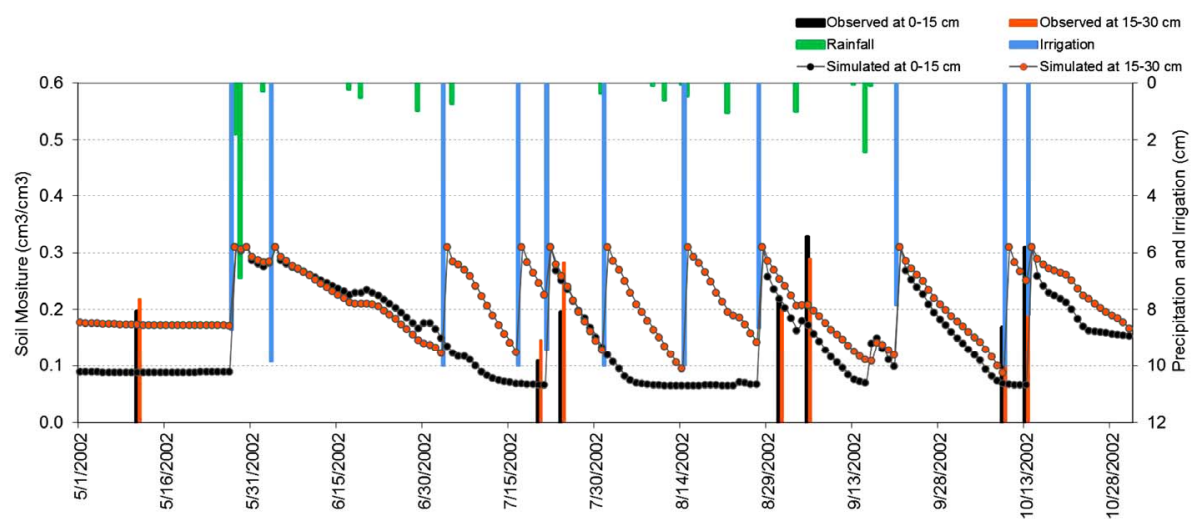

Figure 5. Simulated and observed soil water content $\left(\mathrm{cm}^{3} / \mathrm{cm}^{3}\right)$ at $0-15 \mathrm{~cm}$ and $15-30 \mathrm{~cm}$ soil depths by SWAP-GA with optimized parameters, rainfall and on-demand irrigation amounts are also shown.

Table 4. The simulated and observed optimized parameters based on 10 generations \& 10 populations.

\begin{tabular}{cccc}
\hline & Emergence & End of Crop & Start of irrigation scheduling \\
\hline Simulated Parameter & 04-June $^{*}$ & 23-October & 02-June \\
Observed Parameter & 20-May (Actual sowing date) & 15-November & 18-May \\
\hline
\end{tabular}

${ }^{*}$ Consider germination period 14 days i.e. Emergence $=$ sowing date + germination period.

by the crop occurred within the top $90 \mathrm{~cm}$ depth, where more than 90 percent of the total root mass found. Figures 5 and 6 shows the soil water depletion till 60 percent as the season progresses. SWAP-GA predicted a total of eleven irrigation applications with irrigation demands varying from $7.8 \mathrm{~cm}$ to $9.9 \mathrm{~cm}$ per application during wheat growth and development period. The major portion of the irrigation demand usually occurs in May, June, August and September months to avoid water stress during critical crop development stages i.e. flowering and fruiting. For cotton, the irrigation demand vary from 7.8 $\mathrm{cm}$ to $9.9 \mathrm{~cm}$ with respect to the irrigation timing, the growth stage of the crop, climate and length of the total growing period. Early development stages show more difference in the actual and potential ET, while mid and late season shows very less difference because of the increased irrigation demand. Cotton crops received regular precipitation during the growing season, and most of it occurred during mid-season. Further, presence of excess water in the root zone early in the growing is expected to restrict root and crop development. Figures 5 shows that, two consecutive irrigations $(8.7 \mathrm{~cm}$ and 9.8 $\mathrm{cm}$ ) during the cotton emergence in early June addition to two precipitation events $(1.8 \mathrm{~cm}$ and $6.9 \mathrm{~cm})$. The precipitation contribution $(17.67 \mathrm{~cm})$ to crop ET mainly during kharif (cotton) which is very low as compared to seasonal irrigation supplies $(102.68 \mathrm{~cm})$ to the fields. Irrigation frequencies are high in mid-season during the flowering stage when the leaf area is at its maximum level. Time series of moisture data indicated that the soil water content at top and bottom layers were quite similar from germination until the date of first precipitation. The top soil layers have slightly lower water contents than lower layers. The model predictions closely matched observations indicating model's ability in simulating soil water content. Root Mean Square Error (RMSE) for simulated and observed soil water content $\left(\mathrm{cm}^{3} / \mathrm{cm}^{3}\right)$ at 0 $-15 \mathrm{~cm}$ is $0.08,15-30 \mathrm{~cm}$ is $0.01,30-60 \mathrm{~cm}$ is 0.001 and $60-90 \mathrm{~cm}$ is 0.01 . The RMSE of simulated and observed soil moisture for four depths provides the minimum possible error. Overall, our results showed that the rainfall contribution to crop ET was very minimal as compared to irrigation supplies to the fields. Although the crest of the soil moisture curve and rainfall matched at some locations, soil moisture tended to rise even though there was no rainfall event.

Figures 5 and $\mathbf{6}$ shows the large ratio of evaporation to precipitation in July/August and has insignificant impact on the soil moisture due to the relatively small precipitation events and less irrigation combined with low temperatures and the soil moisture can be maintained to a constant level. The top soil layers have slightly lower water contents than lower layers. It is because the top layer forms the sphere of life, which receives moisture in pulses of precipitation and irrigation. From Figures 5 and 6 , it also reveals that the top $30 \mathrm{~cm}$ of the soil experienced greater soil moisture fluctuations than in soil layer below. It is because the top layer forms the sphere of life that receives moisture in pulses of precipitation and irrigation while a major portion of that water is extracted through evaporation and transpiration by plants. The simulated and observed soil moisture levels showed 


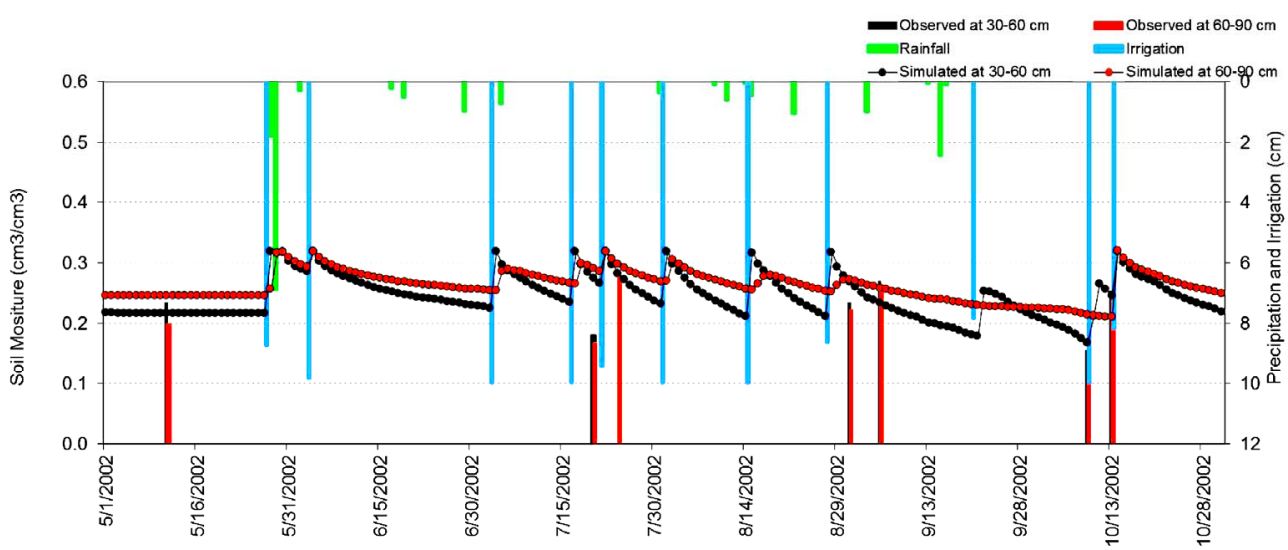

Figure 6. Simulated and observed soil water content $\left(\mathrm{cm}^{3} / \mathrm{cm}^{3}\right)$ at $30-60 \mathrm{~cm}$ and $60-90 \mathrm{~cm}$ soil depths by SWAP-GA with optimized parameters, rainfall and on- demand irrigation amounts are also shown.

increasing trend from June to September, and then decreased onwards, which coincided with occurrence of irrigation and precipitation. Lowest level of moisture in the soil profile was simulated for August when plants are transpiring at a maximum rate (Figure 3). However, this phenomenon did not occur in the observed data. In SIC, it is very common to have very dry conditions late in the growing season and it can reduce crop yields if soil water content is is not available. As the water table depth increases, the soil layer tends to hold more water with no fluctuations throughout the season. The Sirsa Irrigation Circle has two water tables, the first one at a depth of 5 $\mathrm{m}$ from the surface and the second at a depth of $15 \mathrm{~m}$. The effect of capillary rise is expected because of the soil type and deep percolation is the main phenomenon for the water flow into various soil layers. Trends in soil moisture predictions follow that in precipitation although the crest of soil moisture curve and precipitation match at some locations. Cotton plant consumes more water and it has high sensitivity to moisture increase. As the crop matures, soil moisture depletion allowances can be greater. The Sirsa soil have storage reserves of 25 to 100 $\mathrm{cm}$ of water which mainly depends on rooting depth of crops grown in this area which makes use of more soil moisture to minimize risk of leaching.

\subsection{Evaluation of Optimized Parameters for Yield Estimation under on-Demand Irrigation Scheduling Scheme}

Table 5 presents a comparison between SWAP-GA predicted and observed crop yield. A general progressive yield was observed with respect to the simulation criteria (with or without On-Demand irrigation). Current cotton yields in the Haryana state is approximately $3500 \mathrm{~kg} / \mathrm{ha}$ under irrigated conditions [21] while SWAP-GA simulated with optimized parameters for on-demand irrigation case showed cotton yield $3686 \mathrm{~kg} / \mathrm{ha}$ and SWAP simulations with observed irrigation and yield dataset at
Table 5. Estimated and observed water balance parameters (cm) for two irrigation cases.

\begin{tabular}{ccc}
\hline Parameters of interest & Case 1 & Case $2^{2}$ \\
\hline Transpiration (cm) & 44.2 & 79.5 \\
Evapotranspiration (cm) & 52.2 & 89.2 \\
Irrigation (cm) & 34.1 & 102.7 \\
Crop dry mass (kg/ha) & 17,170 & 18,701 \\
Harvesting Index & 21.47 & 21.47 \\
Total production of cotton (Seed+Lint) & 3687 & 4015.1 \\
Ginning percentage & 37.1 & 37.11 \\
Lint weight (kg/ha) & 1368 & 1490 \\
\hline
\end{tabular}

${ }^{1}$ SWAP-GA simulations with optimized parameters for on-demand irrigation. ${ }^{2}$ SWAP simulations with observed irrigation and yield dataset at farmer's field.

farmer's field showed $4015 \mathrm{~kg} / \mathrm{ha}$.

The SWAP-GA simulations show that crop water needs supplied by on-demand irrigation increased lint yield response to the progressively greater irrigation capacity treatments. Table $\mathbf{6}$ shows estimated and observed water balance parameters $(\mathrm{cm})$ for two irrigation cases. The models indicate that the water use efficiency of cotton increased from 0.15 to $0.4 \mathrm{~kg} / \mathrm{m}^{3}$ based on irrigation while 0.17 to $0.26 \mathrm{~kg} / \mathrm{m}^{3}$ by ET (Table 6) which indicating considerable variation and scope exists for improvements in WUE based on calibrated parameters. In Haryana, successful crop production is not possible without supplemental irrigation because of erratic precipitation events. Irrigation application by the calibrated model and on-demand irrigation, the water use efficiency obtained from the on-demand is increased considerably without water deficit. Factors responsible for the low WUE-values include both the relatively high fractions of soil evaporation in the ET term and of water percolation from the irrigation water applied. 
Table 6. Water use efficiency (WUE, $\mathrm{kg} \cdot \mathrm{m}^{-3}$ ) for two irrigation case studies.

\begin{tabular}{ccc}
\hline Water Use Efficiency $^{3}$ & ${\text { Case } 1^{1}}^{1}$ & Case $2^{2}$ \\
\hline WUE $_{\mathrm{T}}\left(\mathrm{kg} \cdot \mathrm{m}^{-3}\right)$ & 0.31 & 0.19 \\
WUE $_{\mathrm{ET}}\left(\mathrm{kg} \cdot \mathrm{m}^{-3}\right)$ & 0.26 & 0.17 \\
WUE $_{\mathrm{IR}}\left(\mathrm{kg} \cdot \mathrm{m}^{-3}\right)$ & 0.40 & 0.15 \\
\hline
\end{tabular}

${ }^{1}$ SWAP-GA simulations with optimized parameters for on-demand irrigation. ${ }^{2}$ SWAP simulations with observed irrigation and yield dataset at farmer's field. ${ }^{3} \mathrm{WUE}_{\mathrm{T}}$, WUE $\mathrm{ET}_{\mathrm{ET}}$, and $\mathrm{WUE}_{\mathrm{IR}}$ are water use efficiencies based on transpiration, evapotranspiration, and irrigation, respectively $\left(\mathrm{kg} \cdot \mathrm{m}^{-3}\right)$.

\section{Summary}

A conceptual modeling methodology was tested in this research to schedule irrigation based on the on-demand strategy using SWAP crop growth model with a genetic algorithm as an optimizer. We used remote sensing ET data to characterize our model via a stochastic data assimilation approach, and then the optimized crop growth parameters were used as inputs to agro-hydrological model. The strength of an integrated data assimilation approach was shown explicitly in the scenario analysis. It was shown that there is a strong relationship between irrigation scheduling, ET, soil water availability, and groundwater table. The effects of ET on the water balance have been demonstrated. It does show that there is a lot of scope for reducing errors in estimated ET to improve water balance estimates. Parameter estimations are successful and the ability of the SWAP-GA to produce ET and soil moisture values accurately in relations with precipitation and irrigation were promising, although the general performance of the model can be described as reasonable. In summary, this study has explored the potential of genetic algorithm to estimate the crop parameters for improving characterization of water management options for predicting soil water content to schedule irrigation.

In this study, the numerical case of 100 generations and 100 populations showed that the GA was able to characterize the terms included in the fitness function very well and parameters could be predictable reasonably well. It has also demonstrated the potential of the data assimilation approach as used in this study is a powerful tool in crop and water parameter estimation for irrigation scheduling. Our results also indicate that the soil moisture profile estimates obtained from this particular synthetic experiment are as good as realistic data. In practice, the feasibility of retrieving subsurface moisture profiles from surface measurements depends on the accuracy and the physical realism of the land surface model and the associated error statistics. Since the subsurface states cannot be remotely sensed at the pixel scale, they can only be estimated by using the hydrologic model to propagate information downward from the surface.

\section{REFERENCES}

[1] D. W. Seckler, U. Amarasinghe, D. Molden, R. De Silva, and R. Barker, "World Water Demand and Supply, 1990 to 2025: Scenarios and Issues," International Water Management Institute (IWMI), Colombo, Research Report No. 19.

[2] B. Kamble and A. Irmak "Combining Remote Sensing Measurements and Model Estimates through Data Assimilation," IEEE International, Vol. 3, 2008, p. 1036.

[3] R. G. Allen, M. Tasumi and R. Trezza. "Satellite-Based Energy Balance for Mapping Evapotranspiration with Internalized Calibration (METRIC)-Model," Journal of Irrigation and Drainage Engineering, Vol. 133, No. 4, 2007, pp. 380-394. doi:10.1061/(ASCE)0733-9437(2007)133:4(380)

[4] M. Anderson, J. Norman, G. Diak, W. Kustas and J. R. Mecikalski. "A Two-Source Time Integrated Model for Estimating Surface Fluxes Using Thermal Infrared Remote Sensing," Remote sensing of Environment, Vol. 60, 1997, pp. 195-216. doi:10.1016/S0034-4257(96)00215-5

[5] W. G. M. Bastiaanssen, M. Menenti, R. A. Feddes and A. A. M. Holtslag. "A Remote Sensing Surface Energy Balance Algorithm for Land (SEBAL): 1. Formulation," Journal of Hydrology, Vol. 212-213, 1998, pp. 198-213. doi:10.1016/S0022-1694(98)00253-4

[6] W. P. Kustas and J. M. Norman, "Use of Remote Sensing for Evapotranspiration Monitoring over Land Surfaces," Hydrological Sciences Journal, Vol. 41, No. 4, 1996, pp. 495-516. doi: 10.1080/02626669609491522

[7] S. P. Loheide and S. M. Gorelick, "A High-Resolution Evapotranspiration Mapping Algorithm (ETMA) with Hydroecological Applications at Riparian Restoration Sites," Remote Sensing of Environment, Vol. 98, 1998, pp. 182-200.

[8] Z. Su, "The Surface Energy Balance System (SEBS) for Estimation of Turbulent Heat Fluxes," Hydrology and Earth System Sciences, Vol. 6, No. 1, 2002, pp. 85-89. doi:10.5194/hess-6-85-2002

[9] B. Seguin, E. Assad, J. P. Freaud, J. P. Imbernon, Y. Kerr, and J. P. Lagouarde, "Use of Meteorological Satellite for Precipitation and Evaporation Monitoring," International Journal of Remote Sensing, Vol. 10, 1989, pp. 1001-1017.

[10] P. H. Gowda, J. L. Chavez, P. D. Colaizzi, S. R. Evett, T. A. Howell and J. A. Tolk, "ET Mapping for Agricultural Water Management: Present Status and Challenges," Irrigation Science, Vol. 26, No. 3, 2008, pp. 223-237. doi:10.1007/s00271-007-0088-6

[11] D. Entekhabi, H. Nakamura and E. G. Njoku, "Solving the Inverse-Problem for Soil Moisture and Temperature Profiles by Sequential Assimilation of Multifrequency Remotely Sensed Observations," IEEE Transactions on Geoscience and Remote Sensing, Vol. 32, No. 2, 1994, pp. 438-448. doi:10.1109/36.295058

[12] A. V. M. Ines, "Improved Crop Production Integration GIS and Genetic Algorithms," Doctoral Thesis, Asian In- 
stitute of Technology, Bangkok, 2002.

[13] B. Kamble, "Evapotranspiration Data Assimilation with Genetic Algorithms and SWAP Model for On-Demand Irrigation", AIT Thesis, 2007.

[14] R. H. Reichle, D. Entekhabi and D. B. McLaughlin, "Downscaling of Radiobrightness Measurements for Soil Moisture Estimation: A Four-Dimensional Variational Data Assimilation Approach," Water Resources Research, Vol. 37, 2001, pp. 2353-2364. doi:10.1029/2001WR000475

[15] M. R. Smith and R. W. Newton, "The Prediction of Root Zone Soil Moisture with a Water Balance-Microwave Emission Model," Master's Thesis, Texas A\&M University, Texas, 1983 .

[16] A. Irmak and B. Kamble, "Evapotranspiration Data Assimilation with Genetic Algorithms and SWAP Model for On-Demand Irrigation," Irrigation Science, Vol. 28, No. 1, 2009, pp. 101-112. doi:10.1007/s00271-009-0193-9

[17] B. Kamble and A. Irmak, "Remotely Sensed Evapotranspiration Data Assimilation for Crop Growth Modeling," In: L. Labedzki, Ed., Evapotranspiration, InTech, 2011. doi: $10.5772 / 13990$

[18] J. C. Van Dam, J. Huygen, J. G. Wesseling, R. A. Feddes, P. Kabat, P. E. V. Van Waslum, P. Groenendjik and C. A. Van Diepen, "Theory of SWAP Version 2.0: Simulation of Water Flow and Plant Growth in the Soil-Water-Atmosphere-Plant Environment," Wageningen Agricultural University and DLO Win and Staring Centre, Wageningen, Technical Document 45, 1997.

[19] D. E. Goldberg, "Genetic Algorithms in Search, Optimization, and Machine Learning," Machine Learning, Vol. 3, No. 2-3, 1988, pp. 95-99. doi:10.1023/A:1022602019183

[20] Y. Chemin, K. Honda, "Spatiotemporal Fusion of Rice Actual Evapotranspiration with Genetic Algorithms and an Agrohydrological Model," IEEE Transactions on
Geosciences and Remote Sensing, Vol. 44, No. 11, 2006 , pp. 3462-3469. doi:10.1109/TGRS.2006.879111

[21] R. S. Malik, R. Kumar, D. S. Dabas, A. S. Dhindwal, S. Singh, U. Singh, D. Singh, J. Mal, R. Singh and J. J. E. Bessembinder, "Measurement program and description database," In: J. C. Van Dam and R. S. Malik, Eds., Water Productivity of Irrigated Crops in Sirsa District, India. Integration of Remote Sensing, Crop and Soil Models and Geographical Information Systems, WATPRO Final Report, 2003, pp. 29-39.

[22] R. Singh, J. C. van Dam and R. A. Feddes, "Water Productivity Analysis of Irrigated Crops in Sirsa District, India," Agricultural Water Management, Vol. 82, No. 3, 2006, pp. 253-278. doi:10.1016/j.agwat.2005.07.027

[23] K. B. Singh, P. R. Gajri and V. K. Arora, "Modelling the Effect of Soil and Water Management Practices on the Water Balance and Performance of Rice," Agricultural Water Management, Vol. 49, No. 2, 2001, pp. 77-95. doi:10.1016/S0378-3774(00)00144-X

[24] L. A. Richards, "Capillary Conduction of Liquids through Porous Mediums," Journal of Applied Physics, Vol. 1, No. 5, 1931, pp. 318-333. doi:10.1063/1.1745010

[25] M. Th Van Genuchten, “A Closed-Form Equation for Predicting the Hydraulic Conductivity of Unsaturated Soils," Soil Science Society of America Journal, Vol. 44, No. 5, 1980, pp. 892-898. doi:10.2136/sssaj1980.03615995004400050002x

[26] J. H. Holland, "Adaptation in Natural and Artificial Systems: An Introductory Analysis with Applications to Biology, Control, and Artificial Intelligence," The University of Michigan Press, Ann Arbor, 1975.

[27] S. Schulze-Kremer, "Molecular Bioinformatics-Algorithms and Applications," Walter de Gruyter, Berlin, 1996, pp. 13-108. 